\title{
EDitorial \\ EDitorial
}

Temas Contemporâneos e Serviço Social: crise do capital, trabalho, assistência social e formação profissional

Desconfiai do mais trivial, na aparência singelo.

E examinai, sobretudo, o que parece habitual.

Suplicamos expressamente: não aceiteis o que é de hábito como coisa natural, pois em tempo de desordem sangrenta, de confusão organizada, de arbitrariedade consciente, de humanidade desumanizada, nada deve parecer natural nada deve parecer impossível de mudar.

Bertold Brecht

É nesta perspectiva que no presente número 20 da Revista Temporalis partilhamos com a categoria profissional temas candentes e contemporâneos da maior importância que portam enorme potencial de seduzir o leitor que não se contente com o que lhe é habitual.

Tendo como eixo a contemporaneidade, todos os artigos enfocam, de alguma maneira, a crise atual e as formas de enfrentá-la, a luta de classes, os diferentes projetos de sociedade e especialmente, as

Temporalis, Brasilia (DF), ano 10, n.20, p.5-9, jul./dez. 2010. 
reformas regressivas com ênfase na contrarreforma da educação, em curso no mundo todo.

A Revista abre com o artigo POLÍTICAS ECONÔMICAS E SOCIAIS NA AMÉRICA LATINA, de Luis Jorge V. Pessoa de Mendonça, no qual o autor problematiza o aparente e paradoxal consenso entre os setores progressistas e conservadores no que se refere a uma avaliação positiva em torno do atual modelo de políticas públicas hegemônico nos países da América Latina. Não obstante, trata de desvelar, por traz do aparente consenso, o modelo de focalização, que repõe a desigualdade social em patamares ainda mais altos. Aponta a interface entre política econômica e políticas sociais focalizadas e assistenciais no capitalismo dependente e mostra os conflitos de interesses que determinam a trajetória das políticas econômicas. Como decorrência, as políticas de intervenção do Estado nos últimos 20 anos perdem seu caráter nacionalista e de mediação entre trabalhadores e capitalistas. Conclui com algumas experiências recentes nos países latino-americanos. Texto de inegável importância para o Serviço Social e áreas afins, tendo em vista seu tema, abordagem critica e abrangência.

Numa interlocução interessante com autores contemporâneos, Danielle Viana Lugo Pereira e Altair Reis de Jesus, no artigo PROJETO DA MODERNIDADE, CRISE CAPITALISTA E IDEOLOGIA PÓS-MODERNA, apontam as controvérsias do projeto da modernidade e a polêmica que os pós-modernos travam com ele, por identificarem a crise capitalista como a crise do projeto fundado pelo iluminismo e pela ilustração. Demonstram que esta crítica torna-se perfeitamente oportuna ao "[...] atual ciclo de reprodução do capital em sua expressão de capital fetiche", com o que é possível concluir que das interpretações da realidade que a tomam - na sua superficialidade e aparência - como simulacro, tanto decorrem interpretações equivocadas quanto as que reivindicam uma critica radical das resultantes do projeto de 


\section{temporalis}

modernização capitalista, que tem sido identificado com a modernidade como um todo.

O atual e instigante artigo de Reivan Marinho de Souza - DE QUE CONTROLE SOCIAL SE TRATA? DO CAPITAL OU DO TRABALHO? tem o mérito de tirar o tema do controle social do senso comum, como muitas vezes tem sido tratado, e analisá-lo a partir da base material na qual ele se insere, ou seja, da sociedade burguesa. Ao buscar tal interpretação na Teoria social de Marx, o artigo preenche uma lacuna na produção crítica do Serviço Social sobre o tema e oferece uma contribuição inegável a outras áreas das ciências sociais aplicadas.

Dentre os temas contemporâneos que vem ganhando espaço no debate profissional, encontra-se a questão da assistencialização da proteção social. Neste rico artigo, intitulado ASSISTENCIALIZAÇÃO DAS POLÍTICAS SOCIAIS: BREVES NOTAS SOBRE O DEBATE CONTEMPORÂNEO, Márcia Nogueira da Silva estabelece uma interlocução com diversos autores buscando desvelar as divergências teóricas e políticas que permeiam o debate, o que torna o artigo mais quente e interessante. Sem dúvida, este é um debate impostergável - o que torna a leitura imprescindível.

Os autores Henrique Wellen e Ranieri Carli problematizam A FALSA DICOTOMIA ENTRE TEORIA E PRÁTICA - clichê muito utilizado no Serviço Social - e a consideram fundada na falsa oposição entre ciência e política. Produzido em linguagem acessível e utilizando argumentos consistentes e fundamentados no marxismo, recolocam temas como é o caso da suposta neutralidade nas ciências sociais, invólucro que sustenta o pensamento burguês, o critério de objetividade e de cientificidade, a práxis, como atividade prática e política. Efetiva contribuição ao debate, este texto recoloca a polêmica de que o Serviço Social, pela sua natureza e

Temporalis, Brasilia (DF), ano 10, n.20, p.5-9, jul./dez. 2010. 
historicidade, tem se constituído como "[...] campo de saber privilegiado para a análise entre teoria e prática social”.

ENADE NO CONTEXTO DE CONTRARREFORMA DO ENSINO SUPERIOR: REFLEXÕES PARA O SERVIÇO SOCIAL, de Larissa Dahmer Pereira, enfoca o polêmico e tão debatido Exame Nacional de Desempenho de Estudantes (ENADE), parte constitutiva do Sistema Nacional de Avaliação do Ensino Superior (SINAES), indicando a necessidade de analisar a relação entre a expansão do ensino superior via setor privado mercantil e a ampliação do sistema de avaliação do ensino superior, no contexto da contrarreforma da educação. Dada sua complexidade e importância, reivindica um amplo debate que envolva os diversos segmentos que protagonizam a formação profissional.

No artigo REESTRUTURAÇÃO PRODUTIVA E HIPERTROFIAÇÃO DA ASSISTÊNCIA SOCIAL: A OFENSIVA DO CAPITAL NO BRASIL, as autoras Sheyla Suely de Souza Silva, Jordeana Davi, Moema Amélia Serpa e Maria Aparecida Nunes dos Santos desenvolvem a hipótese de que há uma estreita relação entre os processos de financeirização, reestruturação produtiva e reestruturação da proteção social, donde a ampliação da assistência social no Brasil através de Programas de transferência de renda e aqueles - pautase nos objetivos de redução dos gastos sociais.

\section{A SITUAÇÃO DA MULHER NA AMÉRICA LATINA E NO CARIBE,} pesquisa empírica realizada por Rosa Marques, Estela Barbosa e Ana Hutz, numa abordagem original e inovadora, problematiza a desigualdade de gênero nos países latino-americanos e caribenhos - região em que, tradicionalmente, essa questão mais se evidencia -, analisando tendências demográficas e do mercado de trabalho dos últimos 20 anos. As autoras retratam também a participação de mulheres na previdência social, sua exposição à violência doméstica, sua participação política em cargos legislativos e, não 


\section{tempordils}

menos importante, enfatizam a chegada da primeira mulher à presidência em nosso pais.

$\mathrm{Na}$ sessão ENSAIO, contamos com o brilhante artigo do economista egípcio e reconhecido intelectual Samir Amin intitulado 2011: A PRIMAVERA ÁRABE? Neste, o autor reflete sobre os desdobramentos possíveis dos acontecimentos que marcam o inicio do ano de 2011 no mundo árabe a que ele denomina de primaveras dos povos árabes. Como movimentos diferentes identifica um denominador comum: proclamam uma revolução antiimperialista, embora nem sempre anticapitalista. Samir Amin busca demonstrar a pontencialidade destas experiências: trata-se de revoltas sociais que cristalizam alternativas, as quais podem, em longo prazo, inscrever-se na perspectiva socialista, donde a luta do capital para desestabilizá-las.

Ademais, contamos ainda com a interessante entrevista com a companheira, assistente social, pesquisadora e docente Márcia Perales, Reitora da Universidade Federal do Amazonas, intitulada A UNIVERSIDADE FEDERAL DO AMAZONAS: UFAM E A SUA INSERÇÃO NA SOCIEDADE AMAZÔNICA, concedida a Elenise Scherer.

Uma última observação se faz necessária: a inegável qualidade dos artigos aqui expostos reflete o nível do debate até o momento alcançado pela área, o que a tem colocado como um importante interlocutor das ciências humanas e sociais. Finalmente, cabe mencionar o esforço coletivo que tem sido realizado por todos nós (comissão editorial, pareceristas, autores) no sentido de ajustar a periodicidade da Revista, mantendo a qualidade que a caracteriza para o que a intervenção das professoras Maria Lucia Garcia e Jussara Mendes, companheiras de viagem, tem sido determinante.

ABEPSS

Gestão 2011-2012

Temporalis, Brasilia (DF), ano 10, n.20, p.5-9, jul./dez. 2010. 
